\title{
BMJ Open Refining clinical algorithms for a neonatal digital platform for low- income countries: a modified Delphi technique
}

\author{
Mari Evans (D) , ${ }^{1}$ Mark H Corden (D) , ${ }^{2,3}$ Caroline Crehan (D) , ${ }^{1}$ Felicity Fitzgerald (D) , ${ }^{1}$ \\ Michelle Heys (D) ${ }^{1}$
}

To cite: Evans M, Corden MH, Crehan C, et al. Refining clinical algorithms for a neonatal digital platform for lowincome countries: a modified Delphi technique. BMJ Open 2021;11:e042124. doi:10.1136/ bmjopen-2020-042124

- Prepublication history and additional online supplemental material for this paper are available online. To view these files, please visit the journal online (http://dx.doi.org/10 1136/bmjopen-2020-042124)

ME and MHC are joint first authors.

Received 26 June 2020 Revised 26 March 2021 Accepted 01 April 2021

A Check for updates

(C) Author(s) (or their employer(s)) 2021. Re-use permitted under CC BY. Published by BMJ.

${ }^{1}$ UCL Institute of Child Health, Great Ormond Street Hospital for Children, London, UK

${ }^{2}$ Division of Hospital Medicine, Department of Pediatrics, Children's Hospital Los Angeles, Los Angeles, California, USA

${ }^{3}$ Department of Pediatrics, University of Southern California Keck School of Medicine, Los Angeles, California, USA

Correspondence to

Dr Michelle Heys;

m.heys@ucl.ac.uk

\section{ABSTRACT}

Objectives To determine whether a panel of neonatal experts could address evidence gaps in local and international neonatal guidelines by reaching a consensus on four clinical decision algorithms for a neonatal digital platform (NeoTree).

Design Two-round, modified Delphi technique. Setting and participants Participants were neonatal experts from high-income and low-income countries (LICS).

Methods This was a consensus-generating study. In round 1, experts rated items for four clinical algorithms (neonatal sepsis, hypoxic ischaemic encephalopathy, respiratory distress of the newborn, hypothermia) and justified their responses. Items meeting consensus for inclusion ( $\geq 80 \%$ agreement) were incorporated into the algorithms. Items not meeting consensus were either excluded, included following revisions or included if they contained core elements of evidence-based guidelines. In round 2, experts rated items from round 1 that did not reach consensus.

Results Fourteen experts participated in round 1, 10 in round 2. Nine were from high-income countries, five from LICs. Experts included physicians and nurse practitioners with an average neonatal experience of 20 years, 12 in LICs. After two rounds, a consensus was reached on 43 of 84 items (52\%). Per experts' recommendations, items in line with local and WHO guidelines yet not meeting consensus were still included to encourage consistency for front-line healthcare workers. As a result, the final algorithms included 53 items (62\%).

Conclusion Four algorithms in a neonatal digital platform were reviewed and refined by consensus expert opinion. Revisions to NeoTree will be made in response to these findings. Next steps include clinical validation of the algorithms.

\section{INTRODUCTION}

Globally, 2.5 million newborns die each year in the first 28 days of life. ${ }^{1}$ Most of these deaths $(98.5 \%)$ occur in low-income countries (LICs), and $40 \%$ occur on the first day of life. ${ }^{2}$ The neonatal mortality rate has halved since $1990,{ }^{3}$ but modelling of global newborn mortality data suggests that a
Strengths and limitations of this study

- In this study, a large number of algorithm items were reviewed and evaluated, and half met consensus for inclusion in the management pathways.

- The review was conducted with experts from a broad range of countries and neonatal experience who simultaneously refined the algorithms and highlighted gaps in current evidence, emphasising the need for future research to support international neonatal guidelines.

- Our study method meant that experts were not able to meet in person, which might have promoted dialogue that would have allowed greater clarity in their collective opinion.

- The representation of neonatal experts from lowincome countries was not as robust as from highincome countries, which may have led to an uneven evaluation of the algorithms.

further two-thirds of current deaths could be prevented if evidence-based solutions were implemented. ${ }^{2}$ One of the WHO Sustainable Development Goals is to end preventable deaths of newborns in all countries and to reduce the neonatal mortality rate from the current rate of 18 per 1000 live births to less than 12 per 1000 by $2030 .{ }^{4}$ Targeting newborn care in LICs is thus an urgent priority, especially the three most common causes of mortality-infections (36\%), prematurity $(28 \%)$ and intrapartum complications $(23 \%){ }^{2}$

The WHO neonatal guidelines are internationally recognised as the leading and most respected source of guidance. ${ }^{5}$ However, one of their limitations is that they are primarily based on data from high-income countries, as there is often a lack of evidence in LICs due to limited diagnostic aids, data and research. ${ }^{6}$ WHO aims to address the challenge of developing setting-appropriate neonatal guidelines by improving stakeholder involvement 
(design guidelines for specific audiences), clarity of presentation (often guidelines are too long and technical) and attention to dissemination. ${ }^{7}$ Mobile health (m-health) technology and digital platforms are potential approaches to implementing these measures and improving the quality of newborn care. ${ }^{8}$

An international team of researchers, clinicians and software developers in the UK, USA, Malawi, Bangladesh and Zimbabwe codesigned and codeveloped with Malawian and Zimbabwean heathcare workers (HCWs) a neonatal digital platform (NeoTree) for facility-based newborn care in LICs. It combines immediate digital data capture (which is shared with HCWs via local dashboards), evidence-based algorithmic clinical decision and management support, newborn education and data linkage to national data systems on one platform. ${ }^{9}$ The algorithms in the Malawian version of the NeoTree support decisions according to established international ${ }^{10}$ and Malawian neonatal guidelines. ${ }^{11}$ In situations where guidelines were not applicable, the NeoTree clinical team used clinical judgement to complete the algorithm development. In the absence of extensive trial or epidemiological data in LICs, alternative techniques to consolidate best available low-quality evidence can be used, such as expert opinion. This study aims to use the modified Delphi technique to determine whether a panel of experts in newborn care can reach a consensus opinion about key clinical decision algorithms used in a digital platform to assist HCWs caring for facility-based unwell newborns in LICs.

\section{METHODS}

\section{Study design}

This study used a two-step modified Delphi technique. ${ }^{12}$ The Delphi technique was chosen because it is an effective method of gathering expert knowledge from geographically diverse leaders in the field to address complex clinical problems that lack evidence.

\section{Recruitment}

Twenty-two neonatal experts were invited to participate in the study. This number represented an adequate sample size $e^{13} 14$ and permitted a manageable amount of data collection. Participants were recruited if they were a physician or neonatal nurse practitioner with more than 10 years neonatal experience (at least three in LICs), neonatal postgraduate training, fluency in English, internet access and willingness to participate. Neonatal experts known to the researchers for their clinical expertise, research and contributions to guideline development in LICs were identified in equal numbers from both LICs and HICs. No financial incentive was offered, but reimbursement for costs of Skype calls was provided for some experts in LICs.

\section{Algorithms and item generation}

The four clinical decision algorithms selected for review were neonatal sepsis, hypoxic ischaemic encephalopathy
(HIE), respiratory distress of the newborn and hypothermia. These conditions represent the leading preventable causes of neonatal mortality and are the most difficult to diagnose and manage appropriately in LICs with some of the weakest WHO grade recommendations and quality of evidence. ${ }^{15}$ For example, the European definition of neonatal sepsis is two or more clinical symptoms and two or more laboratory signs in the presence of, or as a result of, suspected or proven infection. ${ }^{16}$ This definition is not possible in LICs where laboratory investigations are not routinely available. ${ }^{17}$

Items were identified by comparing the algorithms side by side with the international (WHO) and local neonatal guidelines (Care of the Infant and Newborn in Malawi-COIN) from which they had been derived. This comparison generated a comprehensive list of items where discrepancies in diagnostic parameters and treatment recommendations required expert opinion. Once finalised, the clinical algorithms and list of items (henceforth referred to as questionnaire) were piloted with two paediatricians with neonatal experience in LICs. Ambiguous items were amended accordingly.

\section{Delphi technique}

The questionnaire was circulated by email to the experts with specific instructions at least 2 weeks before they were interviewed. Each algorithm was verbally and diagrammatically explained with their references specified (ie, WHO, COIN or NeoTree research team) to aid in decision-making during the interview (online supplemental file 1). Round 1 interviews were conducted in June and July 2018. Experts were sent up to two reminder emails to schedule their phone or Skype interview. Interviews were conducted privately from a home office. Standardised questions were used to review each item from the questionnaire. Experts were asked to rate their level of agreement for including an item in an algorithm using a five-point Likert scale. A five-point scale was chosen because evidence suggests that a five-point scale appears to be less confusing than a seven-point scale and to increase expert response rate. ${ }^{18}$ Each rating was followed by openended questions to obtain the experts' rationale for their response and any amendment or additional items they would propose. All interview data were transcribed using both audiorecordings and notes made during the interview by the facilitator. All responses were anonymised (with participant numbers) and reviewed together with the quantitative results.

The upper limit of agreement among experts has been recommended to be set at $80 \%$ ( 4 or higher on the Likert scale) for Delphi studies. ${ }^{13}$ Due to our sample size, this upper limit was used to apply greater rigour to item inclusion. Items that met consensus ( $\geq 80 \%$ agreement) were included or were modified with minor changes to wording based on expert advice. Items that did not meet consensus $(<80 \%)$ were removed or modified according to the feedback from the expert panel and submitted for the second round. Items that did not meet consensus 
were still included if they were part of WHO and COIN guidelines so that frontline HCWs continued to follow the current standard of care. A second questionnaire was designed with modified items and expert additions from the first round (eg, inclusion of the Thompson encephalopathy score ${ }^{19}$ ).

In round 2 (June and July 2019), this second questionnaire was distributed electronically to the 14 experts from round 1 (online supplemental file 1). A results summary from round 1 was sent to the experts, and the full set of anonymised results were made available at their request. Two email reminders were sent to non-responders. Experts again rated items on a Likert scale and explained their ratings. Responses were analysed as described in round 1 , and items meeting $\geq 80 \%$ consensus were kept for the final NeoTree algorithms.

\section{Patient and public involvement}

While key stakeholders were involved in codeveloping the NeoTree digital platform, there was no patient or public involvement in this Delphi study.

\section{Consent procedures}

The goals and processes of the project were explained to the experts in their email invitation, and consent was obtained by email agreement. Experts were verbally informed at the beginning of the first round that their responses would be kept anonymous.

\section{RESULTS}

Twenty-two neonatal experts were invited to participate. Sixteen responded; one declined due to lack of financial incentive, and one declined due to conflict of interest. All respondents had work experience in Africa; one respondent had over 20 years of clinical experience in Malawi and contributed to the development of the COIN guidelines. Demographics of the expert panel are listed in table 1 .

\section{Round 1}

Fourteen experts (63\% response rate) completed round 1. Interviews averaged $73 \mathrm{~min}$ (40-110 min). Thirtyfour items $(45 \%)$ reached consensus (figure 1). These items were either: (1) included, unmodified (32\%); (2) included, modified (11\%) or (3) changed for clarification in the second round (2\%). Items that did not reach consensus (55\%) were either: (1) excluded from the revised algorithm (30\%); (2) included because they were part of WHO/COIN guidelines or the Thompson score $(11 \%)$ or (3) changed and submitted for a second round (14\%) (table 2).

The expert panel consistently stated that algorithm items must comply with WHO danger signs and COIN guidelines for neonatal sepsis, irrespective of whether the panel agreed with them. For example, experts thought that 'bulging fontanelle' was 'subjective; there are noninfectious causes ... many babies' fontanelles bulge
Table 1 Characteristics of the Delphi panel from round 1

\begin{tabular}{|c|c|c|}
\hline & Characteristics & $n=14(\%)$ \\
\hline \multirow[t]{2}{*}{ Location } & Experts from HICs & $9(64)$ \\
\hline & Experts from LICs & $5(36)$ \\
\hline \multirow[t]{3}{*}{ Level of expertise } & Neonatologist & $6(43)$ \\
\hline & Paediatrician & $6(43)$ \\
\hline & ANNP & $2(14)$ \\
\hline \multirow{2}{*}{$\begin{array}{l}\text { Years of neonatal } \\
\text { experience following } \\
\text { graduate degree } \\
(\text { mean } \pm S D)\end{array}$} & Overall & $20( \pm 12)$ \\
\hline & In LICs & $12( \pm 7)$ \\
\hline \multirow{3}{*}{$\begin{array}{l}\text { Work experience in } \\
\text { LICs }\end{array}$} & Africa & $14(100)$ \\
\hline & Asia & $7(50)$ \\
\hline & Central America & $4(28)$ \\
\hline \multirow{6}{*}{$\begin{array}{l}\text { Country of medical } \\
\text { degree }\end{array}$} & UK & 7 \\
\hline & USA & 2 \\
\hline & South Africa & 2 \\
\hline & Rwanda & 1 \\
\hline & Sudan & 1 \\
\hline & Zimbabwe & 1 \\
\hline
\end{tabular}

ANNP, advanced neonatal nurse practitioner; HICs, high-income countries; LICs, low-income countries.

when they just cry.' Another item that did not meet consensus was 'poor feeding,' which experts found vague for multiple reasons, including: 'it is too subjective; it depends on how long for ... many newborns do not feed well on the first day of life.' However, experts agreed that poor feeding was a sign of possible sepsis if it was 'a new onset of poor feeding when the infant had previously been feeding well.' This item was changed to 'new onset of poor feeding' for the final algorithm.

Two items that were included because they are part of the COIN guidelines highlighted inconsistencies with WHO guidelines. For example, COIN uses a temperature of more than $37.5^{\circ} \mathrm{C}$ as a fever for a newborn, while WHO and most experts use more than $38^{\circ} \mathrm{C}$. Therefore, $37.5^{\circ} \mathrm{C}$ was included for the Malawian digital platform, but $38^{\circ} \mathrm{C}$ will be used for other countries. Other items where a difference between the recommendations and the guidelines occurred were antibiotic choice and duration for neonatal sepsis.

Modifications usually involved adopting the language used by WHO or COIN, but there were items that experts felt needed clarifying. For example, experts felt that 'twitching or abnormal movements' needed to be added to the WHO term 'convulsions' because seizures in a neonate can be very subtle. Certain items that could not be revised easily were submitted for the second round according to feedback from the expert panel. For example, experts disagreed that 'very/extremely premature $(<32$ 
Figure 1. Outcome of algorithm items after round one and round two of Delphi technique.

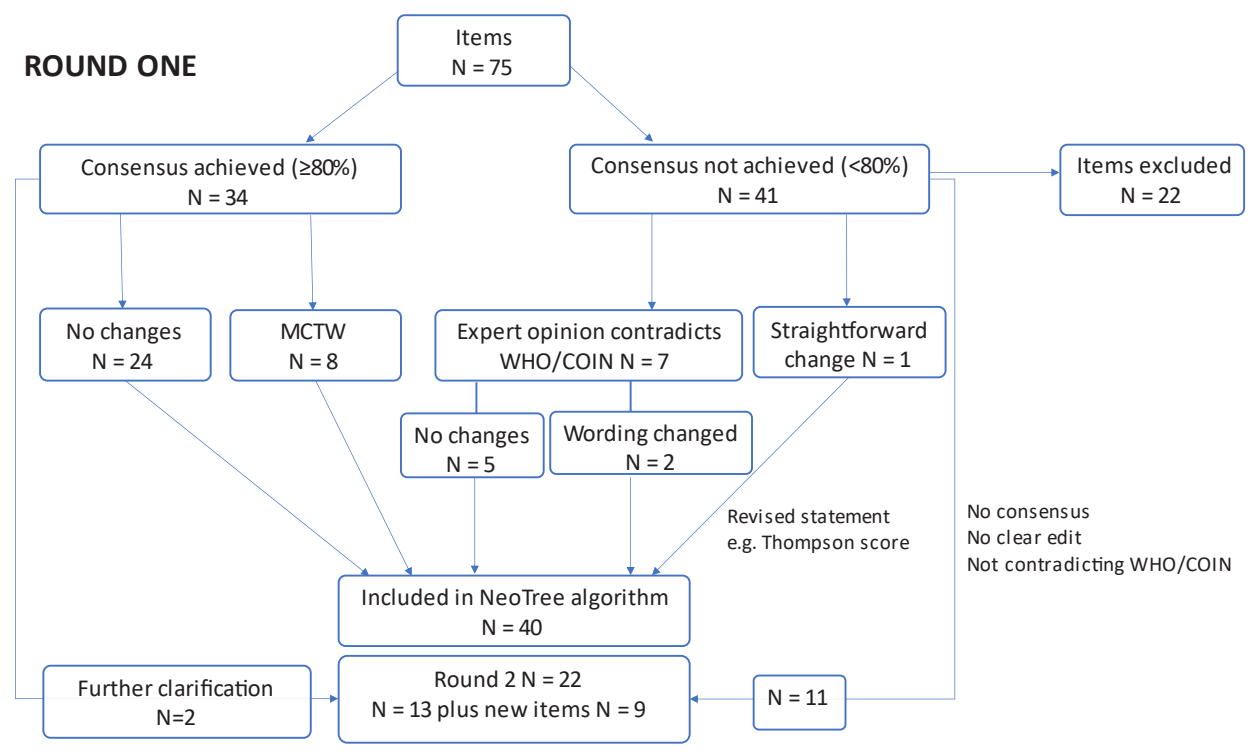

ROUND TWO

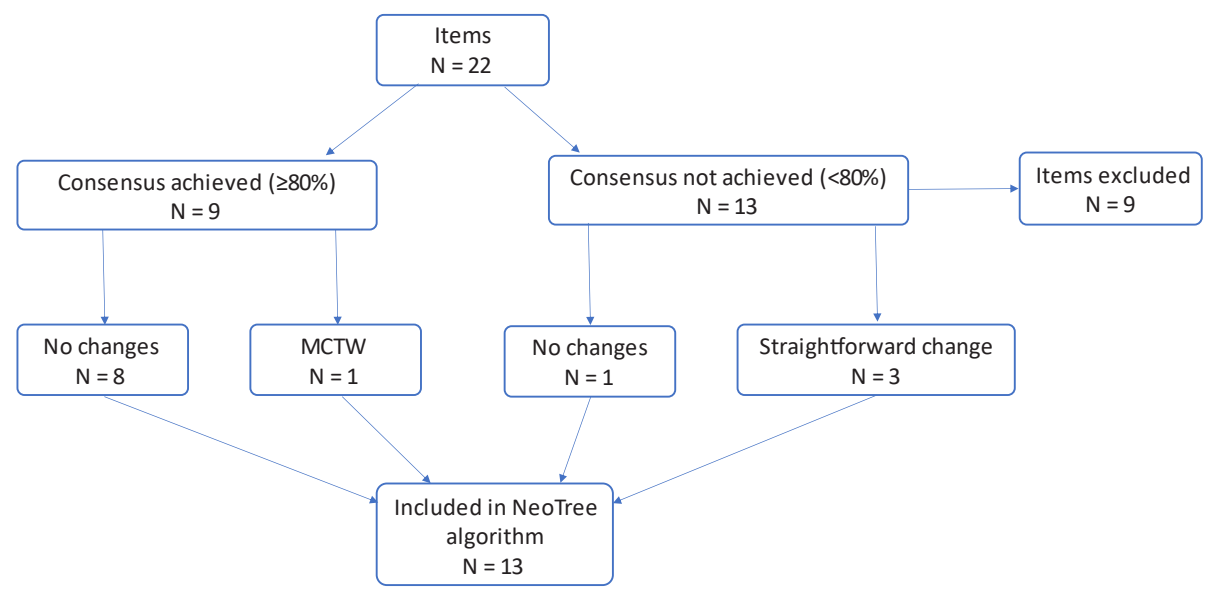

Abbreviations: $\mathrm{COIN}=$ Care of the Infant and Newborn in Malawi; $\mathrm{MCTW}=$ minor changes to wording; $\mathrm{WHO}=$ World Health Organisation

Figure 1 Outcome of algorithm items after round 1 and round 2 of the Delphi technique. COIN, Care of the Infant and Newborn; MCTW, minor changes to wording.

weeks gestation)' was a major risk factor for sepsis if 'the baby was delivered as a clean cold caesarean section for maternal reasons and the mother was not in labour.' Eighty per cent of experts highlighted that the algorithm should include weight to guide gestation because 'gestation is often unknown' and 'you are relying on [the] Ballard score ${ }^{20}$ which has plus or minus 2 weeks accuracy.' Similar opinions regarding method of delivery and the importance of birth weight were expressed for 'slightly premature (32-36 weeks gestation).' Both gestational age brackets were submitted into the second round as risk factors for sepsis after modifying the items to include $\mathrm{WHO}$ weight parameters to guide gestation.
Other items that did not gain consensus and were submitted for the second round included items that experts felt needed further clarification. 'Born before arrival' as a minor risk factor for sepsis was clarified to the experts that this meant the baby was born en-route to the hospital (either in a vehicle or on the roadside, both being considered dirty environments in Malawi). A 'neonate admitted with or history of a fever' as a minor risk factor for sepsis was changed to 'mother reports a non-measured fever' in the second round. Lastly, because experts considered the term 'birth injury' unclear, we asked them in round 2 to define what they considered a 'significant birth injury.' 
Table 2 Round 1 heat chart to show which items met consensus and their outcomes

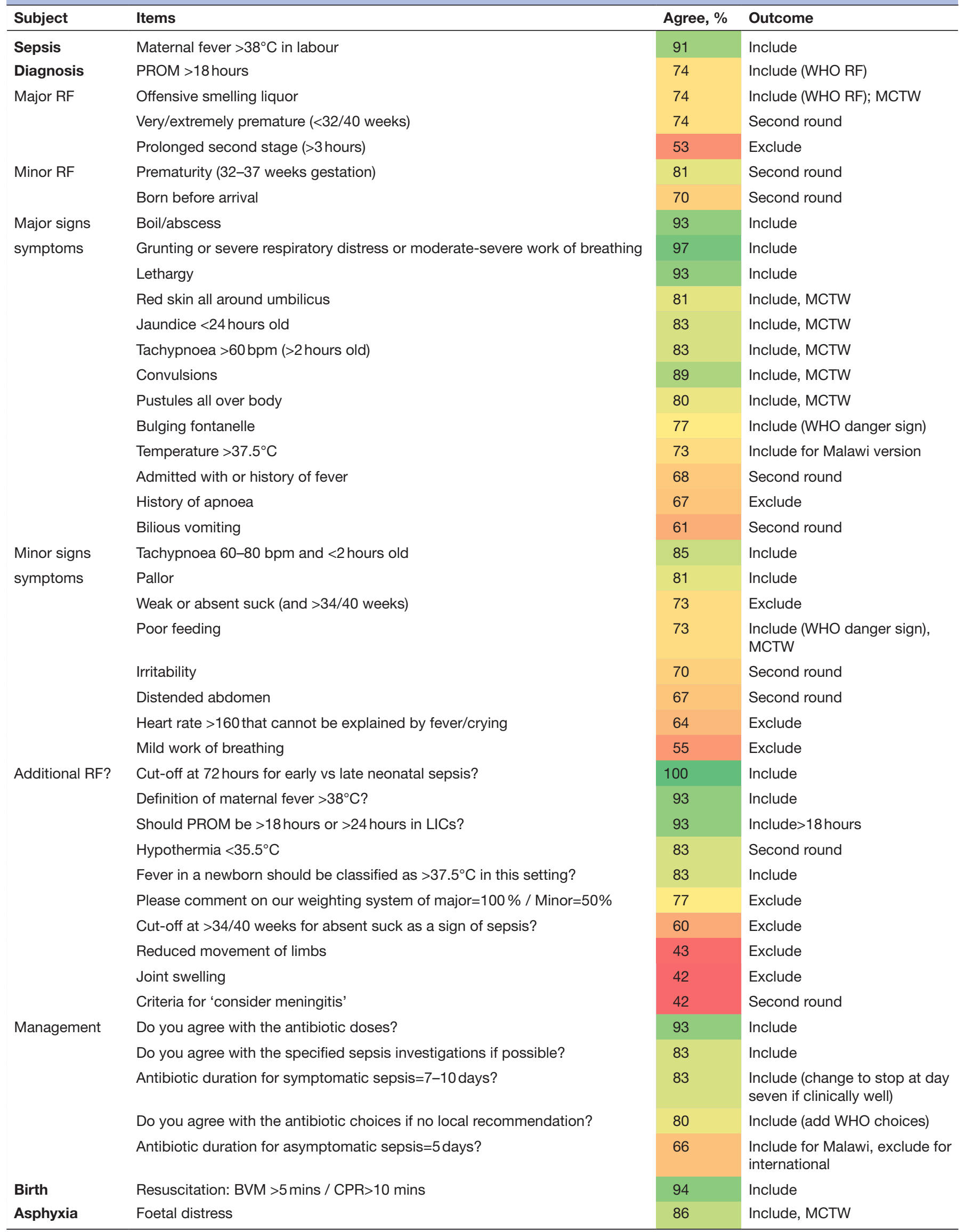




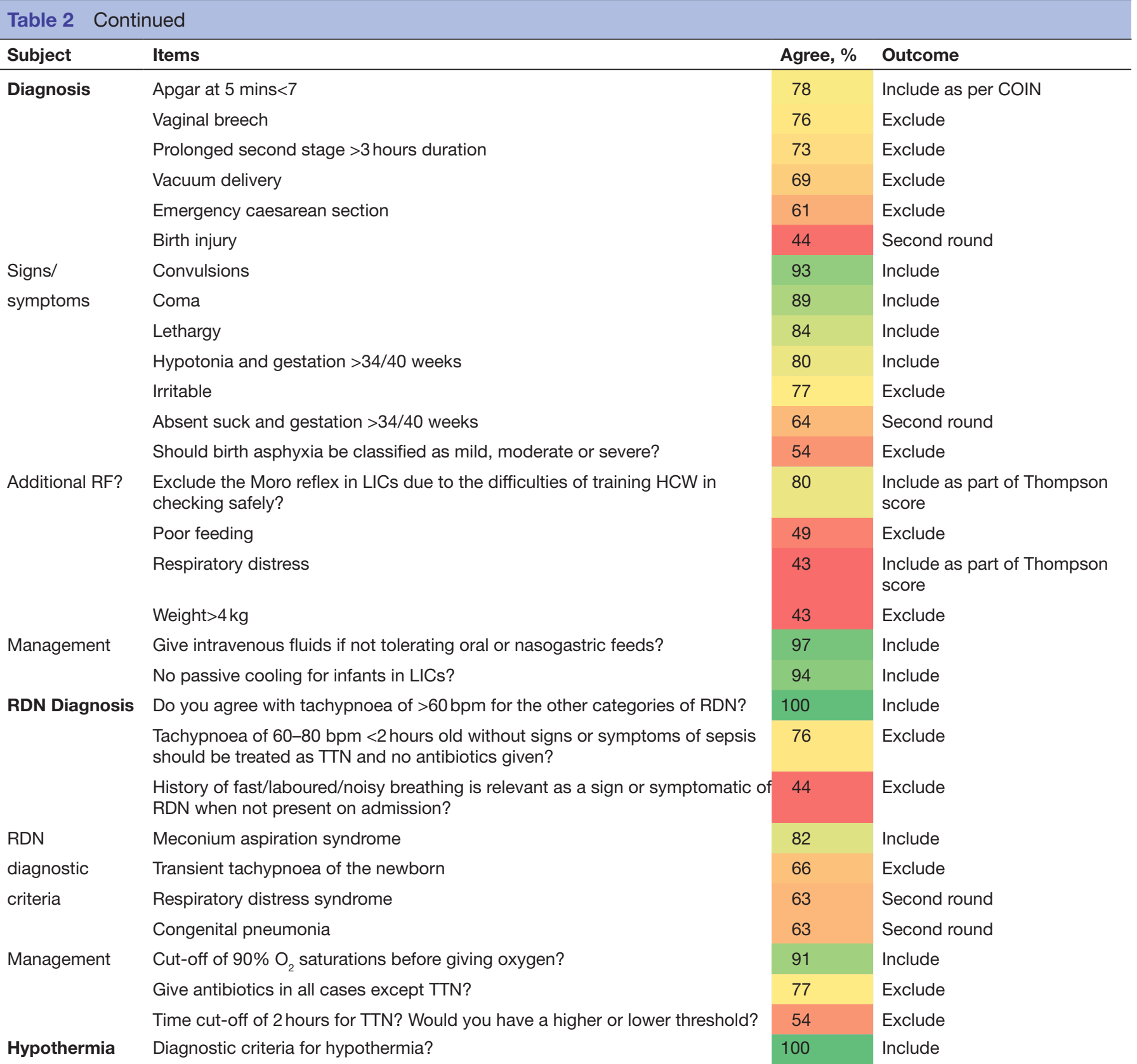

BPM, breaths per minute; BVM, bag valve mask; COIN, Care of the Infant and Newborn; CPR, cardiopulmonary resuscitation; HCW, heathcare worker; LICs, low-income countries; MCTW, minor changes to wording; PROM, prolonged rupture of membranes; RDN, respiratory distress of the newborn; RF, risk factor; TTN, transient tachypnoea of the newborn.

\section{Key findings by algorithm}

The first important finding was that the 'major' or 'minor' algorithmic weighting system (where one major risk factor for sepsis is equivalent to two minors) used to diagnose neonatal sepsis was near consensus $(77 \%)$ but did not meet the $80 \%$ threshold. Experts called for further evidence before adopting this system: It is a difficult thing to do...you need to work out how specific and sensitive the app is by looking at blood cultures.' Two experts suggested using a sepsis risk score calculator, and another two experts highlighted that WHO only uses danger signs. This weighting system was subsequently removed from the algorithm.
The second significant algorithmic finding was on HIE. An academic expert in neonatal encephalopathy discouraged the use of the term 'birth asphyxia,' a term used by Malawian HCWs and therefore incorporated into the original algorithm.

You really must not call it birth asphyxia because birth asphyxia means failing to breathe at birth and what you are talking about is encephalopathy.

Additional feedback on the algorithm focused on the combination of risk factors or clinical signs and symptoms to consider or diagnose HIE. Experts cited a lack of evidence for using risk factors to diagnose birth asphyxia 
and that the digital platform should only be using clinical signs and symptoms.

Birth asphyxia is not about risk factors. If you have encephalopathy, it is a clinical diagnosis, and it is irrelevant what your risk factors are.

Experts recommended using a validated encephalopathy score, ${ }^{19}{ }^{21}$ which was incorporated into the HIE algorithm. The risk factors that met consensus may be used as prompts to perform the Thompson score, which uses clinical signs and symptoms exclusively to diagnose HIE.

Third, for the respiratory algorithm, experts highlighted that 'It is hard to make an accurate diagnosis of a respiratory condition without investigations.' Therefore, the algorithm should focus instead on the management of respiratory distress. All respiratory conditions (respiratory distress syndrome, meconium aspiration, congenital pneumonia and transient tachypnoea of the newborn (TTN)) now fall under the umbrella diagnosis of respiratory distress of the newborn within the algorithm. For teaching purposes, the four respiratory conditions will be included as 'diagnoses to consider' in the management.

Finally, for the hypothermia algorithm, experts commented that first-line treatment for all newborns be skin-to-skin care including those who were severely hypothermic $\left(<32^{\circ} \mathrm{C}\right)$ unless they showed any signs or symptoms of being unstable. Additionally, experts did not think it was realistic to review a newborn every $15-30 \mathrm{~min}$ when hypothermic. No major revisions were made to the hypothermia algorithm.

\section{Round 2}

Ten $(71 \%)$ experts completed round 2, seven electronically and three by telephone interview. Four experts dropped out (three from HICs, one from LIC); three did not respond to email reminders and one expert was unable to meet the completion deadline. Nine items $(41 \%)$ reached consensus (figure 1$)$. These items were either (1) included, unmodified (36\%) or (2) included, modified in the revised algorithm (5\%). Items that did not reach consensus (59\%) were either (1) excluded

\begin{tabular}{|c|c|c|c|}
\hline Subject & Items & Agree, $\%$ & Outcome \\
\hline $\begin{array}{l}\text { Sepsis } \\
\text { diagnosis }\end{array}$ & $<32 / 40$ weeks gestation and/or $<1500 \mathrm{~g}$ & 82 & Include \\
\hline \multirow[t]{2}{*}{ 'Other' RF } & Babies born en route to the hospital & 54 & Exclude \\
\hline & Mother reports a non-measured fever & 52 & Exclude \\
\hline symptoms & $\begin{array}{l}\text { Do you think a one-off } \mathrm{T}<35.5^{\circ} \mathrm{C} \text { should be added as a sign of neonatal sepsis } \\
\text { in an LIC? }\end{array}$ & 44 & Exclude \\
\hline \multirow{2}{*}{$\begin{array}{l}\text { Additional } \\
\text { RF? }\end{array}$} & Swollen red eyelids with pus & 88 & Include \\
\hline & Unconscious & 86 & Include, MCTW \\
\hline Consider & Drowsy, lethargic or unconscious with $\mathrm{T}>37.5^{\circ} \mathrm{C}$ & 96 & Include \\
\hline \multirow[t]{4}{*}{ Meningitis } & Bulging fontanelle with $\mathrm{T}>37.5^{\circ} \mathrm{C}$ & 94 & Include \\
\hline & Irritability with a high-pitched cry with $\mathrm{T}>37.5^{\circ} \mathrm{C}$ & 92 & Include \\
\hline & Abnormal movements/twitching or convulsions with $\mathrm{T}>37.5^{\circ} \mathrm{C}$ & 90 & Include \\
\hline & Abnormal tone with $\mathrm{T}>37.5^{\circ} \mathrm{C}$ & 80 & Include \\
\hline \multirow{2}{*}{$\begin{array}{l}\text { HIE } \\
\text { diagnosis }\end{array}$} & Do you agree with absent suck and gestation $<32 / 40$ weeks as a sign of HIE? & 42 & Exclude \\
\hline & How should we describe 'significant' birth injury as a risk factor for HIE? & 20 & Exclude \\
\hline $\begin{array}{l}\text { RDN } \\
\text { diagnosis }\end{array}$ & $\begin{array}{l}\text { Do you agree with gestation }<34 / 40 \text { for part of the diagnostic criteria for } \\
\text { respiratory distress syndrome? }\end{array}$ & 74 & $\begin{array}{l}\text { Include, change to } \mathrm{WHO} \\
\text { definition }\end{array}$ \\
\hline
\end{tabular}

HIE, hypoxic ischaemic encephalopathy; LICs, low-income countries; MCTW, minor changes to wording; RDN, respiratory distress of the newborn; $\mathrm{RF}$, risk factor; $\mathrm{T}$, temperature. 


\section{ORIGINAL}
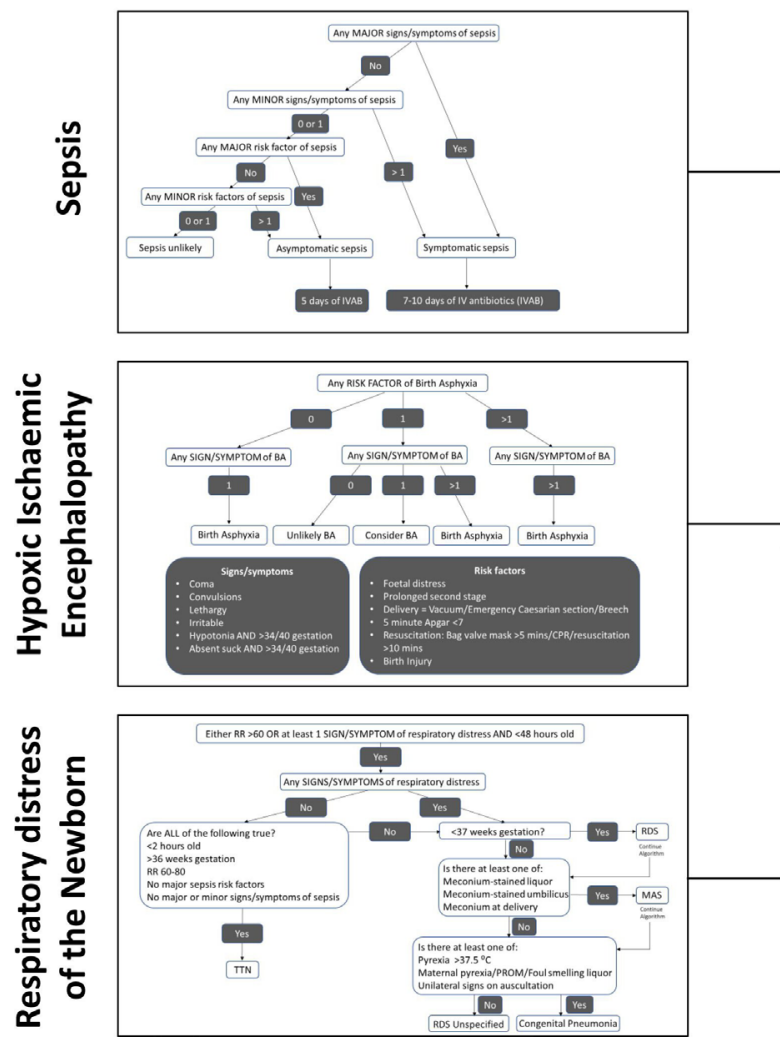

\section{REVISED}
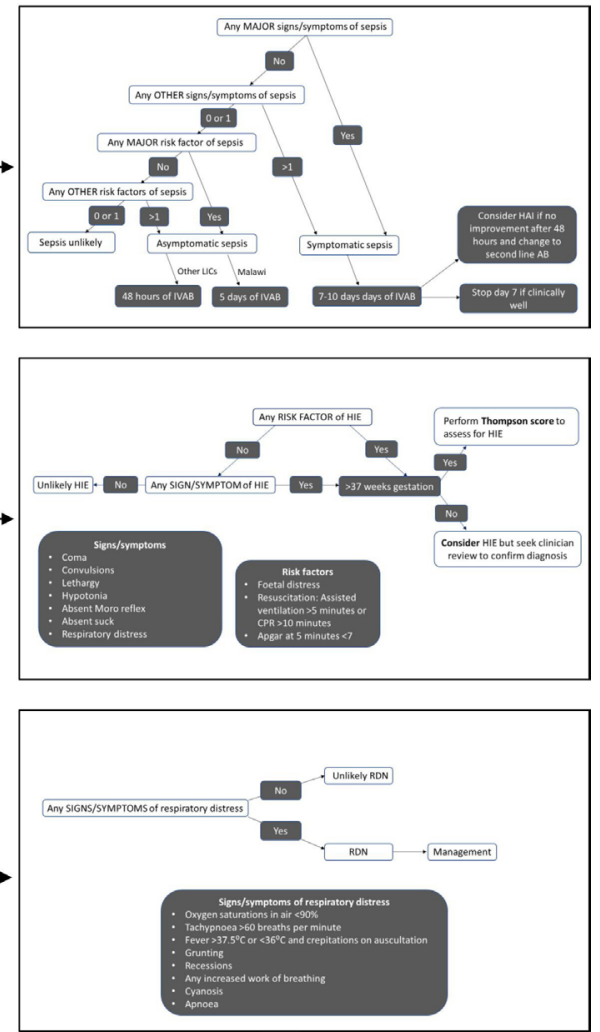

Figure 2 Modification of the algorithms as a result of the Delphi technique. AB, antibiotics; BA, birth asphyxia; CPR, cardiopulmonary resuscitation; HAI, hospital-acquired infection; HIE, hypoxic ischaemic encephalopathy; LICs, low-income countries; MAS, meconium aspiration; RDN, respiratory distress of newborn; RDS, respiratory distress syndrome; RR, respiratory rate; TTN, transient tachypnoea of newborn.

$(41 \%)$ or (2) included, modified according to WHO guidelines or expert suggestion (18\%) (table 3 ).

In round 1, experts indicated that hypothermia was a major sign of sepsis and should be included in the sepsis algorithm if persistent. In round 2, we clarified that the digital platform is to be used at the time of admission onto the neonatal unit, at which point the HCW will only have one temperature reading. Experts in round 2 disagreed that a single temperature reading of $<35.5^{\circ} \mathrm{C}$ was a sign of sepsis and felt that it would more likely be due to environmental hypothermia, a common problem in LICs. Additionally, in round 2, it was established that experts were much more concerned with extremely premature and/or $<1500 \mathrm{~g}$ neonates (88\% consensus) compared with slightly premature and/or $1500-2500 \mathrm{~g}$ neonates (62\% consensus) being at risk for neonatal sepsis. Central cyanosis was an addition to the second round as an expert suggestion to include all WHO danger signs; despite missing consensus (with $78 \%$ agreement), it was ultimately included in the final sepsis algorithm to comply with WHO guidelines for danger signs.

All of the respiratory items marginally missed consensus. All three items were still included in the education sections of the digital platform with revisions in line with WHO diagnostic criteria. Modifications to the algorithms can be found in figure 2 and online supplemental file 2 .

\section{DISCUSSION}

We report the use of a modified Delphi technique to review digital clinical pathway algorithms for four neonatal conditions managed by HCWs in LICs. Approximately two-thirds $(62 \%)$ of the original algorithm items were ultimately included for use in the NeoTree digital platform based on consensus expert opinion and national/ international guidelines. The NeoTree team revised the algorithms based on this feedback. Expert discussion emphasised gaps in evidence in neonatal care in LICs, highlighting areas for future research.

Each algorithm had components that triggered debate among the experts. For neonatal sepsis, three points were discussed. First, experts called for further evidence before adopting a 'major' and 'minor' algorithmic weighting system to diagnose neonatal sepsis. In response, the NeoTree research team are conducting a study in Zimbabwe and Malawi looking at which clinical indicators are predictors of positive blood cultures. Second, there was disparity in opinion regarding whether to give prophylactic antibiotics and the duration of antibiotics for newborns with risk factors for sepsis who remain clinically well without any supporting investigations (NeoTree's equivalence to asymptomatic sepsis). The WHO recommendation to administer prophylactic antibiotics for a neonate with maternal risk factors for sepsis is considered 
weak with very low-quality evidence. ${ }^{22}$ Despite reaching a consensus on particular risk factors (prolonged rupture of membranes, maternal fever), experts also highlighted the evidence base as weak. In terms of duration of treatment for asymptomatic sepsis, while expert opinion varied, the Malawian guidelines recommend a 5-day course ${ }^{11}$ while WHO recommends 2 days. ${ }^{15}$ The NeoTree algorithms will therefore keep to local and international recommendations, but the NeoTree team will feed back to the Malawian COIN expert panel that consensus suggested 5 days is too long to treat newborns with sepsis risk factors only. Third, experts disputed the treatment choice and duration for symptomatic neonatal sepsis; incidentally, WHO recommendations lack strong evidence or efficacy. ${ }^{17}$

For the HIE algorithm, the Thompson score was preferred because it is simpler to perform, less time consuming and better at predicting poor outcomes in moderate and severe HIE during the first hours of life compared with the Sarnat score at 24 hours. ${ }^{19}$ The NeoTree research team suspected that measures such as examining for posturing and Moro reflex would be relatively complicated for frontline HCWs with minimal training to assess. However, neonatal experts' experience and previous studies in $\mathrm{LICs}^{23}$ assured the team that the score is relatively straightforward to teach.

Several points of discussion also centred on the respiratory algorithms. First, experts noted that even with investigations in HICs respiratory conditions may be difficult to diagnose. ${ }^{24}$ Second, despite experts' concerns about antibiotic overprescribing in LICs and the need to differentiate TTN from other respiratory conditions, they did not think this was currently feasible in LICs due to limitations in HCW capacity, resources and knowledge. Thus, experts agreed that all neonates with signs of respiratory distress should have respiratory support and antibiotics. A recent study justified the use of antibiotics for tachypnoea alone in a neonate in a resource-limited setting. ${ }^{25}$ Third, experts recommended performing chest X-rays (if available) only if imaging would change management (eg, a longer course of antibiotics for congenital pneumonia) or if the neonate was deteriorating.

With the proliferation of clinical digital platforms in HICs and LICs, there is growing concern with the quality and safety standards of their clinical guidance. Countries and organisations (including WHO) are now taking measures to ensure application developers fulfil a strict set of criteria to protect patients. ${ }^{26}$ While the Delphi technique can establish expert consensus, it may also strengthen the safety and quality standards of clinical algorithms. This technique has been widely used in developing paper-based neonatal clinical guidelines in HICs and LICs. ${ }^{27-29}$ There are also studies that have used the Delphi technique to develop items used in m-health tools. ${ }^{30-32}$ Our study is unique in the application of this technique to develop algorithms on a digital platform specific to neonatal care in low-resource settings.

This study has several limitations. The choice of using a modified two-step Delphi process meant that a final face-to-face meeting was not possible, which may have prevented some exchange of important information to clarify differences in expert opinion. However, this method allowed for the contributions of geographically dispersed experts, maintained their anonymity and prevented them from conforming to other experts. The recruitment of more experts from HICs (64\%) compared with LICs (36\%), despite originally inviting equal numbers to participate, could have contributed to expert panel bias. We invited three Malawian clinicians as experts; the absence of their input could be another limitation, since the algorithms had initially been contextualised to the Malawian setting. However, the end goal of NeoTree development is to be applicable in a wide range of resource-limited settings; therefore, experts with a broad geographical range of clinical experience were recruited. Drop-outs from the first to the second round could have affected the consensus level and contributed to attrition bias.

Some factors may have contributed to selection bias. The Delphi process is time intensive, which could have meant that those clinicians who are busier with perhaps even more clinical expertise or those with limited internet access (mainly LICs) could not participate. Additionally, offering a financial incentive might have obtained a more equal representation of experts. Another drawback of the Delphi being a labour-intensive process was that a year elapsed between the two rounds. Experts may have forgotten the algorithms and items from the first round in the second round if they did not read the summary of results or refresh their knowledge of the algorithms. Experts reported that they found the layout of the second questionnaire confusing; a redesign contributed to delays.

This study used the Delphi technique to refine four clinical decision algorithms in a neonatal digital platform designed for HCWs in LICs to standardise and improve the quality of newborn care. The key to implementing the NeoTree algorithms in other LICs will be to demonstrate that clinical algorithms in a digital platform versus paper-based guidelines can aid HCWs in making faster, more accurate diagnoses and provide better, more cost-effective treatment that will ultimately improve the quality of newborn care and reduce mortality. This will require a large-scale clinical-trial evaluation. Ultimately, with consensus opinion shaping the algorithms of this digital platform, accurate data capture, immediate clinical assessment and optimal medical care may be achieved to improve neonatal outcomes.

Acknowledgements We thank all the participants of the Delphi surveys for their invaluable contributions to revise the clinical algorithms and highlight open questions, including Dr Helen Brotherton, Dr Simbarashe Chimhuya, Dr Cath Harrison, Dr Tyler Hartmann, Dr Hammad Khan, Dr Camilla Kindgon, Dr Tom Lissauer, Dr Azza Mashumba, Kathy Mellor (MBE), Professor Elizabeth Molyneux, Dr Cally Tann, Dr Cliff O'Callahan, Susan Quinton, and Dr Raissa Teteli. We would also like to thank Dr Brian Corden and Dr Alice Myers for their reviews of the manuscript.

Contributors $\mathrm{CC}$ led the development of the original algorithms refined in this paper, supervised by MH.ME, CC and MH conceived the study, generated the 
methodology and designed the questionnaires. ME conducted the interviews and analysed the data. ME and MHC produced the first draft and contributed equally to this manuscript. CC, FF and MH provided edits and comments to the draft. All authors reviewed and approved the final version of the manuscript.

Funding This work was supported in part by the Wellcome Trust Digital Innovation Award (215742/z19/z). FF is supported by the Academy of Medical Sciences, the funders of the Starter Grant for Clinical Lecturers scheme and the UCL Great Ormond Street NIHR Biomedical Research Centre.

Disclaimer The funders had no role in the study design, data collection and analysis, or preparation of the manuscript.

Competing interests $\mathrm{CC}$ and $\mathrm{MH}$ are cofounders of the NeoTree platform and continue to conduct research related to its development. FF and $\mathrm{MH}$ are trustees of the NeoTree Foundation. The NeoTree platform is a not-for-profit product; none of the coauthors benefit financially.

\section{Patient consent for publication Not required.}

Ethics approval Ethics approval was not required for this study according to the University College of London Research Ethics Committee.

Provenance and peer review Not commissioned; externally peer reviewed.

Data availability statement Data are available on reasonable request. All data relevant to the study are included in the article or uploaded as online supplemental information.

Supplemental material This content has been supplied by the author(s). It has not been vetted by BMJ Publishing Group Limited (BMJ) and may not have been peer-reviewed. Any opinions or recommendations discussed are solely those of the author(s) and are not endorsed by BMJ. BMJ disclaims all liability and responsibility arising from any reliance placed on the content. Where the content includes any translated material, BMJ does not warrant the accuracy and reliability of the translations (including but not limited to local regulations, clinical guidelines, terminology, drug names and drug dosages), and is not responsible for any error and/or omissions arising from translation and adaptation or otherwise.

Open access This is an open access article distributed in accordance with the Creative Commons Attribution 4.0 Unported (CC BY 4.0) license, which permits others to copy, redistribute, remix, transform and build upon this work for any purpose, provided the original work is properly cited, a link to the licence is given, and indication of whether changes were made. See: https://creativecommons.org/ licenses/by/4.0/.

\section{ORCID iDs}

Mari Evans http://orcid.org/0000-0001-5113-3629

Mark H Corden http://orcid.org/0000-0001-6146-1634

Caroline Crehan http://orcid.org/0000-0002-3655-6954

Felicity Fitzgerald http://orcid.org/0000-0001-9594-3228

Michelle Heys http://orcid.org/0000-0002-1458-505X

\section{REFERENCES}

1 WHO. Newborns: reducing mortality, 2019. Available: https://www. who.int/news-room/fact-sheets/detail/newborns-reducing-mortality [Accessed May 2020].

2 Lawn JE, Blencowe H, Oza S. Every newborn: progress, priorities, and potential beyond survival. Lancet 2014;384:189-205

3 WHO. Levels \& trends in child mortality: report 2019. Estimates developed by the UN Inter-agency Group for Child Mortality Estimation, 2019. Available: https://www.unicef.org/reports/levelsand-trends-child-mortality-report-2019 [Accessed May 2020].

4 WHO. WHO guidelines Approved by the guidelines review committee, 2015. Available: https://www.who.int/publications/ guidelines/guidelines_review_committee/en/ [Accessed Jun 2019].

5 WHO. WHO recommendations on newborn health: guidelines approved by the WHO guidelines review Committee, 2017. Available: https://www.who.int/publications/i/item/WHO-MCA-17.07 [Accessed Feb 2021].

6 Becker JU, Theodosis C, Jacob ST. Surviving sepsis in low-income and middle-income countries: new directions for care and research. Lancet Infect Dis 2009;9:577-82.

7 TDV Global. Evaluation of the impact of WHO publications, 2016. Available: https://www.who.int/docs/default-source/documents/ evaluation/report-evaluation-impact-who-publications.pdf?sfvrsn= 577627c5_2 [Accessed Feb 2021].
8 Hall CS, Fottrell E, Wilkinson S, et al. Assessing the impact of mHealth interventions in low- and middle-income countries-what has been shown to work? Glob Health Action 2014;7:25606.

9 Crehan C, Kesler E, Nambiar B. The NeoTree application: developing an integrated mHealth solution to improve quality of newborn care and survival in a district hospital in Malawi. BMJ Glob Health 2019;4:e000860.

10 WHO. Pocket book of hospital care for children: guidelines for the management of common childhood illnesses. 2nd edn, 2013. https:// apps.who.int/iris/handle/10665/81170

11 COIN Course. Care of the infant and newborn in Malawi. The coin course participants manual, 2017. Available: http://cms.medcol.mw/ cms_uploaded_resources/41905_12.pdf [Accessed Jun 2018].

12 Sinha IP, Smyth RL, Williamson PR. Using the Delphi technique to determine which outcomes to measure in clinical trials: recommendations for the future based on a systematic review of existing studies. PLoS Med 2011;8:e1000393.

13 Hsu CC, Sandford BA. The Delphi technique: making sense of consensus. Prac Assess Res Evaluat 2007;12.

14 Akins RB, Tolson $\mathrm{H}$, Cole BR. Stability of response characteristics of a Delphi panel: application of bootstrap data expansion. BMC Med Res Methodol 2005;5:37.

15 WHO. Recommendations for management of common childhood conditions: evidence for technical update of pocket book recommendations: newborn conditions, dysentery, pneumonia, oxygen use and delivery, common causes of fever, severe acute malnutrition and supportive care, 2012. Available: https://apps.who. int/iris/bitstream/handle/10665/44774/9789241502825_eng.pdf? sequence $=1$ [Accessed Jun 2019].

16 European Medicines Agency. Report on the expert meeting on neonatal and paediatric sepsis, 2010. Available: https://www.ema. europa.eu/en/documents/report/report-expert-meeting-neonatalpaediatric-sepsis en.pdf [Accessed Jul 2019].

17 Obiero CW, Seale AC, Berkley JA. Empiric treatment of neonatal sepsis in developing countries. Pediatr Infect Dis J 2015;34:659-61.

18 Babakus E, Mangold WG. Adapting the SERVQUAL scale to hospital services: an empirical investigation. Health Serv Res 1992;26:767-86.

19 Thompson CM, Puterman AS, Linley LL, et al. The value of a scoring system for hypoxic ischaemic encephalopathy in predicting neurodevelopmental outcome. Acta Paediatr 1997;86:757-61.

20 Ballard JL, Khoury JC, Wedig K. New Ballard score, expanded to include extremely premature infants. J Pediatr 1991;119:417-23.

21 Sarnat HB, Sarnat MS. Neonatal encephalopathy following fetal distress: a clinical and electroencephalographic study. Arch Neurol 1976;33:696-705.

22 Ungerer RLS, Lincetto O, McGuire W, et al. Prophylactic versus selective antibiotics for term newborn infants of mothers with risk factors for neonatal infection. Cochrane Database Syst Rev 2004;4:CD003957

23 Bhagwani DK, Sharma M, Dolker S, et al. To study the correlation of thompson scoring in predicting early neonatal outcome in post asphyxiated term neonates. J Clin Diagn Res 2016;10:SC16-19.

24 Costa S, Rocha G, Leitão A, et al. Transient tachypnea of the newborn and congenital pneumonia: a comparative study. J Matern Fetal Neonatal Med 2012;25:992-4.

25 Tikmani SS, Muhammad AA, Shafiq Y. Ambulatory treatment of fast breathing in young infants aged. Clin Infect Dis 2017;64:184-9.

26 van Haasteren A, Gille F, Fadda M. Development of the mHealth APP Trustworthiness checklist. Digit Health 2019;5:205520761988646.

27 Kamath-Rayne BD, Thukral A, Visick MK, et al. Helping babies breathe, second edition: a model for strengthening educational programs to increase global newborn survival. Glob Health Sci Pract 2018;6:538-51.

28 Balikuddembe MS, Tumwesigye NM, Wakholi PK, et al. Expert perspectives on essential parameters to monitor during childbirth in low resource settings: a Delphi study in sub-Saharan Africa. Reprod Health 2019;16:119.

29 Housseine N, Punt MC, Browne JL, et al. Delphi consensus statement on intrapartum fetal monitoring in low-resource settings. Int J Gynaecol Obstet 2019;146:8-16.

30 Bakibinga $\mathrm{P}$, Kamande $\mathrm{E}$, Omuya $\mathrm{M}$, et al. The role of a decisionsupport smartphone application in enhancing community health volunteers' effectiveness to improve maternal and newborn outcomes in Nairobi, Kenya: quasi-experimental research protocol. BMJ Open 2017;7:e014896.

31 Fung JST, Akech S, Kissoon N, et al. Determining predictors of sepsis at triage among children under 5 years of age in resource-limited settings: a modified Delphi process. PLoS One 2019;14:e0211274 
32 Pellé KG, Rambaud-Althaus C, D’Acremont V, et al. Electronic clinical decision support algorithms incorporating point-of-care diagnostic tests in low-resource settings: a target product profile. BMJ Glob Health 2020;5:e002067. 